\title{
ТЕОРЕТИЧЕСКАЯ ЭКОНОМИЧЕСКАЯ МОДЕЛЬ УТИЛИЗАЦИИ ЗОЛОШЛАКОВЫХ ОТХОДОВ УГОЛЬНЫХ ТЭС В РОССИИ
}

\section{A THEORETICAL ECONOMIC MODEL OF COAL COMBUSTION PRODUCT UTILIZATION IN RUSSIA}

I. Zolotova

Summary. This article considers the key factors that determine the economic feasibility of utilization of coal combustion products of thermal power plants (CCP). The paper identified 4 main factors: the cost of production of ash and slag materials, transport and logistics costs, alternative cost in the form of waste disposal costs and value for the end user. It was found that if the value to the end user is higher than the cost of CCP preparation then utilization is deemed to be economically viable. The conclusion indicates the need to develop a set of measures to create economic incentives and regulatory restrictions aimed at reducing the feasibility of placing the CPP on landfills to achieve the targets set by the Energy strategy of the Russian Federation for the period up to 2035.

Keywords: ecology of power energy, waste utilization, coal ash, Energy Strategy 2035, economics of waste utilization.

\author{
Золотова Ирина Юрьевна \\ ФГОБУВО «Финансовый университет при \\ Правительстве Российской Федерации» \\ IYZolotova@fa.ru
}

Аннотация. Данная статья рассматривает ключевые факторы, определяющие экономическую целесообразность утилизации продуктов сжигания твердого топлива (золошлаков) угольных теплоэлектростанций (ПСТТ-ЗШ0). В работе были определены 4 основных фактора: стоимость производства золошлаковых материалов, транспортно-логистические расходы, альтернативная стоимость в виде затрат на размещение отходов и ценность для конечного потребителя. Было установлено, что экономическая целесообразность возникает в том случае, если ценность для конечного потребителя выше, нежели затраты ТЭС по подготовке необходимой продукции. В заключении указывается необходимость разработки комплекса мероприятий по формированию экономических стимулов и регуляторных ограничений, направленных на снижение целесообразности размещения ПСТТ-ЗШо на золошлакоотвалах для достижения целевых ориентиров, определенных Энергетической стратегией Российской Федерации на период до 2035 года.

Ключевые слова: экология энергетики, утилизация отходов, золошлаки ТЭС, Энергостратегия-2035, экономика утилизации отходов.

влекательности их использования в деятельности предприятий-потребителей в России. Данный подход основан на работах Ward, Heidrich и Yeatman [1], в которых выделялись 4 основных фактора, определяющих экономическую целесообразность вовлечения золошлаков в хозяйственный оборот:

- расходы на производство золошлаковых материалов (ЗШМ);

- расходы на транспортировку золошлаков до места их утилизации;

- альтернативная стоимость в виде сохранения практики накапливания отходов и несения сопутствующих расходов;

- ценность золошлакового материала для потребителя.

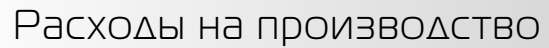 золош^аковых материалов}

Для успешной реализации системного вовлечения ПСТТ-ЗШО в хозяйственный оборот со стороны ТЭС должны быть предусмотрены все мероприятия по получению статуса продукции/материала (ЗШМ) для производимых ПСТТ-ЗШО в соответствии с федеральным законом № 184 от 27.12.2002 «О техническом регулиро- 
вании». Подобные мероприятия предполагают разработку технической и стандартизирующей документации: технологический регламент, технические условия, стандарт организации. С целью нивелирования рисков претензий со стороны надзорных органов в области охраны окружающей среды также необходимо прохождение государственной экологической экспертизы (ГЭЭ) на технологии производства ЗШМ. Данная процедура требует проведения анализа микробиологических показателей, химического состава, физическо-механических свойств и др. В зависимости от решения государственного органа исполнительной власти срок действия положительного заключения может действовать от 3 до 5 лет. Совокупно данные мероприятия могут быть затратными на уровне ТЭС и, следовательно, становиться стоп-фактором для активизации деятельности по системной утилизации ПСТТ-ЗШО.

Существенные расходы ТЭС могут быть связаны с модернизацией системы золоудаления. На большинстве отечественных ТЭС используется система гидрозолоудаления (ГЗУ), которая позволяет образовывать только гидратированную золошлаковую смесь (ЗШС). ЗШМ, полученные путем переработки ЗШС, имеют низкую ценность для потребителей и, как правило, реализуются для потребителей по минимальной цене. В случае наличия потенциала использования золошлаков в строительной отрасли для ТЭС может быть целесообразным переход на систему сухого/пневмо золоудаления (ПЗУ). Подобное технологическое решение позволяет ТЭС образовывать сухую-золу уноса, которая имеет цементирующие свойства (зависит от доли содержания оксида кальция), позволяющие ее использовать в качестве вяжущего компонента вместо портландцемента. Однако для успешной работы данной системы требуется комплексное решение, предусматривающее обустройство:

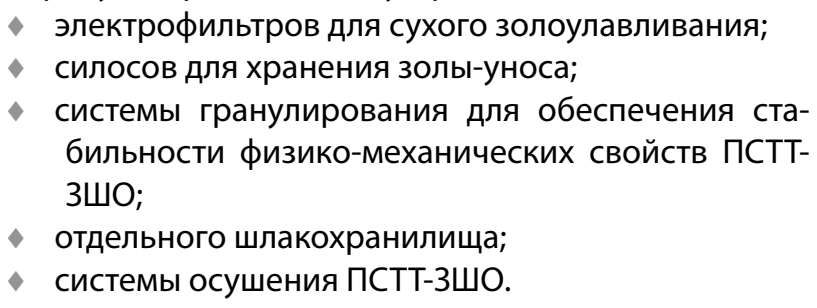

Переход на систему сухого золоудаления является капиталоемким проектом, который зачастую сопоставим по объему расходов со строительством нового золоотвала. В связи с отсутствием устойчивого рынка сбыта ЗШМ многие ТЭС в России на сегодняшний день не практикуют систему сухого золоудаления.

\section{Транспортно-логистические расхомы}

Расходы на транспортировку ЗШО от места их образования/размещения до объекта утилизации могут стать существенным барьером для организации системного вовлечения. Для большинства направления утилизации ЗШО транспортные расходы занимают существенную долю в себестоимости. Тем самым, даже априорно низкая себестоимость производства золошлаков может быть нивелирована в случае существенного расстояния золоотвалов/ТЭС от потенциальных потребителей. Согласно оценкам Ассоциации развития золошлаковой индустрии Австралии (ADAA), использование золошлаков для ликвидации горных выработок в Австралии экономически целесообразно только в случае, если золоотвал расположен не более чем в 20 км от объекта рекультивации [2].

Сложившаяся практика в России показывает, что мероприятия по рекультивации также будут сопровождаться эксплуатационными затратами, связанными с сооружением подъездной дороги на выделенной площадке под рекультивацию нарушенных земель, перевозкой золошлаков (включая погрузку/разгрузку), работами на площадке под рекультивацию (включая посев трав). Наибольшую долю (свыше 70\%) в структуре соответствующих эксплуатационных затрат занимают затраты, связанные с перевозкой золошлаков.

В работе Лунева [3] была проведена оценка экономической целесообразности использования ЗШС в качестве грунта для сооружения дорожной насыпи. В основе оценки был заложен фактор транспортного плеча. Стоимость транспортировки и реализации ЗШС сопоставлялась с использованием более распространенных глинистых и песчаных грунтов. Результаты оценки, представленные на рисунке 1, можно интерпретировать так, что транспортное плечо для доставки ЗШО может быть в 4,5 раза длиннее, нежели радиус перевозок для более распространенных грунтов, при этом сохраняя экономическую конкурентоспособность. Подобная экономия возникает в связи с тем, что глинистые или песчаные грунты предполагают более сложные и, следовательно, более затратные операции по подготовке материала к использованию.

Приведенный выше расчет осуществлялся исходя из прямых экономических затрат. Потенциальные расходы ТЭС на расширение или сооружение новых золоотвалов не учитывались. Тем самым нельзя исключать, что для ряда ТЭС, находящихся в критической ситуации в части заполненности золоотвалов, экономически целесообразно будет реализовывать ПСТТ-ЗШО ниже себестоимости с целью исключения будущих капитальных затрат на строительство нового объекта размещения отходов. Несмотря на то, что капитальные затраты на строительство золоотвалов могут частично компенсироваться за счет регулируемых цен (тарифов) на тепловую и электрическую энергию, сдерживающие механизмы роста тарифов могут приводить к необходимости покрытия 


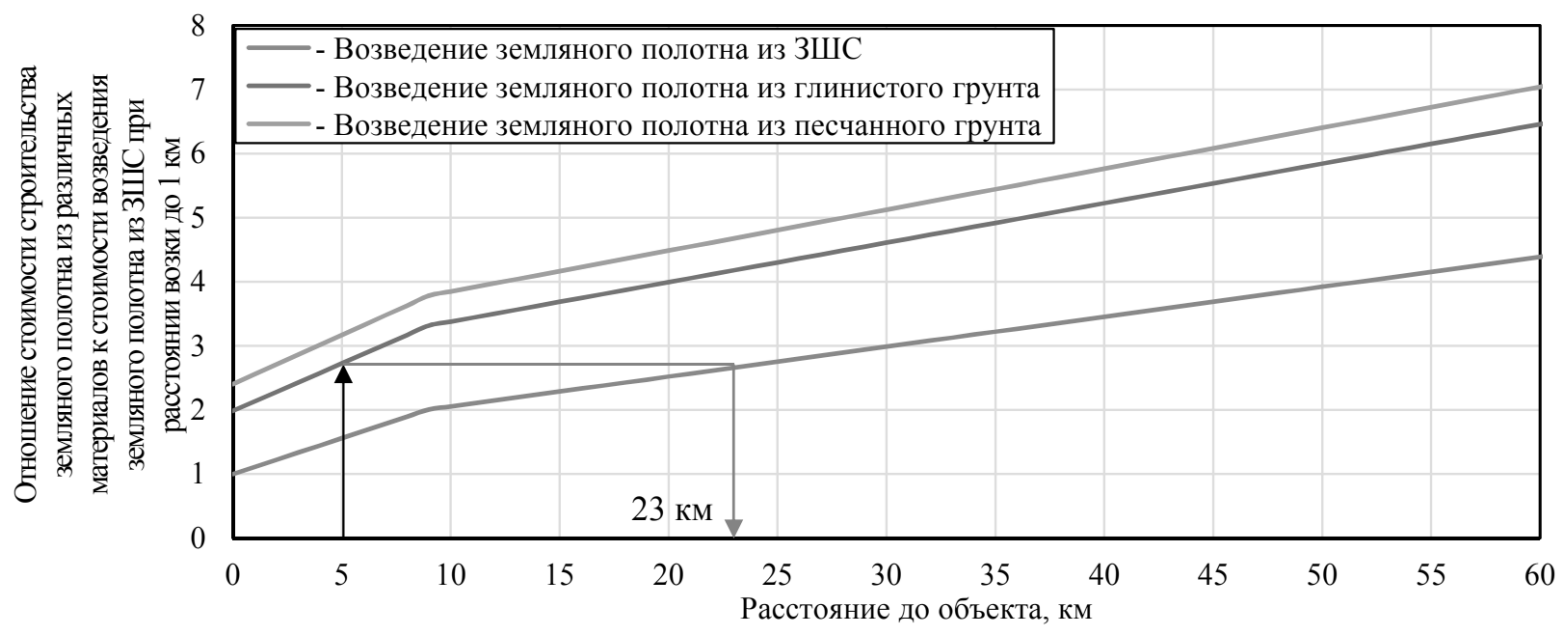

Рис. 1. Сравнение экономической целесообразности использования золошлаковой смеси для дорожной насыпи по сравнению с традиционными грунтами. Источник: исследование Лунева А. А. [3]

данных расходов со стороны бюджетных источников, либо самих генерирующих компаний.

\section{Расходы на обслуживание системы обрашения с ПСТТ-ЗШО}

Дополнительной финансовой нагрузкой на угольные ТЭС становится плата за размещение отходов, которая относится к платежам за негативное воздействие на окружающую среду (НВОС). Данные платежи осуществляют предприятия, формирующие в ходе производства отходы различного класса опасности в течение отчетного периода и размещающие их на сертифицированных объектах размещения отходов (ОРО). Ставки платы за НВОС утверждаются Постановлением Правительства Российской Федерации. В соответствии с Постановлением Правительства РФ от 13.09.2016 N913 (ред. от 24.01.2020) «О ставках платы за негативное воздействие на окружающую среду и дополнительных коэффициентах», ставка за размещение промышленных отходов $V$ класса опасности в 2018 года (помимо добывающей и перерабатывающей промышленности), к которым относятся 99\% всех образующихся в России объемов ЗШО-ПСТТ, составляла 17,3 руб. за 1 т [4]. Ставка платы за НВОС ежегодно индексируется в соответствии с инфляцией.

В настоящее время согласно положениям Правил технической эксплуатации электрических станций и сетей Российской Федерации [5] (пункты 4.10.11 и 4.10.32) при эксплуатации золошлакоотвалов должно быть обеспечено предотвращение загрязнения золой воздушного бассейна и окружающей территории, для чего на каждой электростанции должны выполняться соответствующие мероприятия по предотвращению пыления. Необходимость следования жестким требованиям по предотвращению экологического вреда со стороны золошлакоотвалов может приводить к существенным затратам для ТЭС.

В соответствии с положениями РД 153-34.0-02.10898 «Рекомендации по борьбе с пылением действующих и отработанных золошлакоотвалов ТЭС» [6] принята следующая классификация мероприятий по пылеподавлению на золошлакоотвалах:

- постоянно действующие мероприятия по пылеподавлению планировочного и конструктивного характера, предусмотренные проектом золошлакоотвала;

- временные оперативные мероприятия по предотвращению пыления поверхностей сухих пляжей золошлакоотвалов, применяемые в процессе эксплуатации, а также при выборке золошлакового материала из отвала для отгрузки потребителям или при производстве работ по наращиванию дамб золошлакоотвала;

- временные технологические мероприятия по предотвращению пыления поверхности уложенных в отвале золошлаков, проводимые В период прекращения эксплуатации секции золошлакоотвала с ее осушением для проведения работ по наращиванию дамб либо в период до выполнения работ по консервации или рекультивации;

- постоянное закрепление отработанной площади золошлакоотвала, выполняемое в целях ее консервации или рекультивации.

В целях оперативного пылеподавления в процессе эксплуатации золоотвала используются соответствующие методы и технические средства такие, как: 
- смачивание пылящих зольных пляжей осветленной водой, подаваемой по пульпопроводам разводящей сети, свободным от золошлаковой пульпы;

- учащение переключения пульповыпусков в теплое время года в целях поддержания в увлажненном состоянии возможно большей поверхности намываемых надводных отложений;

- периодическое орошение водой сухих пляжей стационарными дождевальными установками или поливочными машинами;

- временный подъем уровня воды отстойного пруда для покрытия водой возможно большей поверхности надводных отложений золошлакового материала.

Также реализуются временные технологические мероприятия, направленные на предотвращение пыления золоотвалов угольных электростанций:

- нанесение на пылящие поверхности золошлакоотвалов слоя грунта;

- закрепление пылящих площадей минеральными либо органическими вяжущими материалами. К рекомендуемым вяжущим материалам относятся: латекс, жидкое стекло, битумы, каменноугольные смолы, различные полимеры;

- уплотнение пылящих поверхностей.

Согласно РД 34.02.303-91 «Отраслевая инструкция по нормированию вредных выбросов в атмосферу для тепловых электростанций и котельных» [7] выброс частиц золы с поверхности золошлакоотвалов рассматривается как сверхнормативный и облагается соответствующими платежами.

Наиболее ощутимым стоимостным фактором в рамках обслуживания системы обращения с ЗшО является необходимость осуществления капиталовложений в расширения емкостей золоотвалов. Объем данных расходов может разниться в зависимости от технологического решения. Увеличение проектной мощности действующего золоотвала (например, наращивание дамбы) может обходиться в сотни миллионов рублей. Тогда как более сложные решения в виде строительства новых золоотвалов связаны с миллиардными инвестициями, а также трудными согласительными процедурами, связанными с получением земельного участка, разрешения на ввод гидротехнического сооружения и др.

\section{ЦенHOCTь}

\section{$\triangle \wedge$ я Конечного потребите^я}

Объем и цена реализации ЗШМ определяется спросом. Тем самым для увеличения спроса на данный вид продукции требуется обоснование технологической возможности использования ЗШМ вместо традиционных материалов и их экономической целесообразности. Чем более дорогой товар реализует потенциальный потребитель, тем выше ценность материалов, используемых для производства данного товара.

Данный тезис на практике успешно подтверждается опытом Китая. В середине 2000-х в Северо-Западном Китае (провинции Внутренняя Монголия и Шаньси) был обнаружен новый вид $3 Ш О-$ - зола с высоким содержанием глинозема (ЗВСГ) [8]. Содержание оксида алюминия в данном виде 3 ШО составляет от $40 \%$ до $50 \%$ общей массы. Китай также является крупнейшим производителем алюминия в мире. Более того, в стране производится больше алюминия, чем ежегодно добывается исходного сырья - бокситов. В связи с этим Китай вынужден существенный объемы бокситов импортировать. Для снижения зависимости от импортных поставок в Китае активно развивается технология извлечения глинозема из ПСТТ-ЗШО. В частности, активно развивается проект по организации крупного глиноземного технопарка при крупнейшей угольной станции в мире - ТЭС Тогто с установленной мощностью в 6,7 ГВт (Внутренняя Монголия, Китай).

Ценность для потребителя может иметь как прямое экономическое выражение, так и определяться косвенно, например, за счет экологических эффектов. Данный тезис особенно актуален для строительной отрасли, которая имеет потенциал снижать объем выбросов углекислого газа за счет использования ЗШМ вместо песка, гравия, глины и клинкера. Именно данный фактор позволил развить масштабное вовлечение ЗШО в строительную отрасль в Австралии и США [9].

\section{Описание

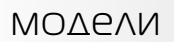

Схематическое описание предлагаемой экономической модели утилизации ПСТТ-ЗШО представлено на рисунке 2.

В основе модели заложен следующий принцип: осуществлять деятельность по утилизации ПСТТ-ЗШО экономически целесообразно, если ценность для потребителя выше по сравнению с затратами ТЭС. В случае ТЭС ключевым вопросом является сопоставление затрат и выгод от двух альтернатив: размещение ПСТТЗШО на золошлакоотвалах или переработка ПСТТ-ЗШО в ЗШМ с последующим вовлечением в хозяйственный оборот. Низкие ставки платы за НВОС, а также возможность компенсировать расходы на строительство и эксплуатацию золоотвалов частично за счет регулируемых цен (тарифов) и бюджетных источников почти сводят к минимуму целесообразность утилизации ПСТТ-ЗШО 


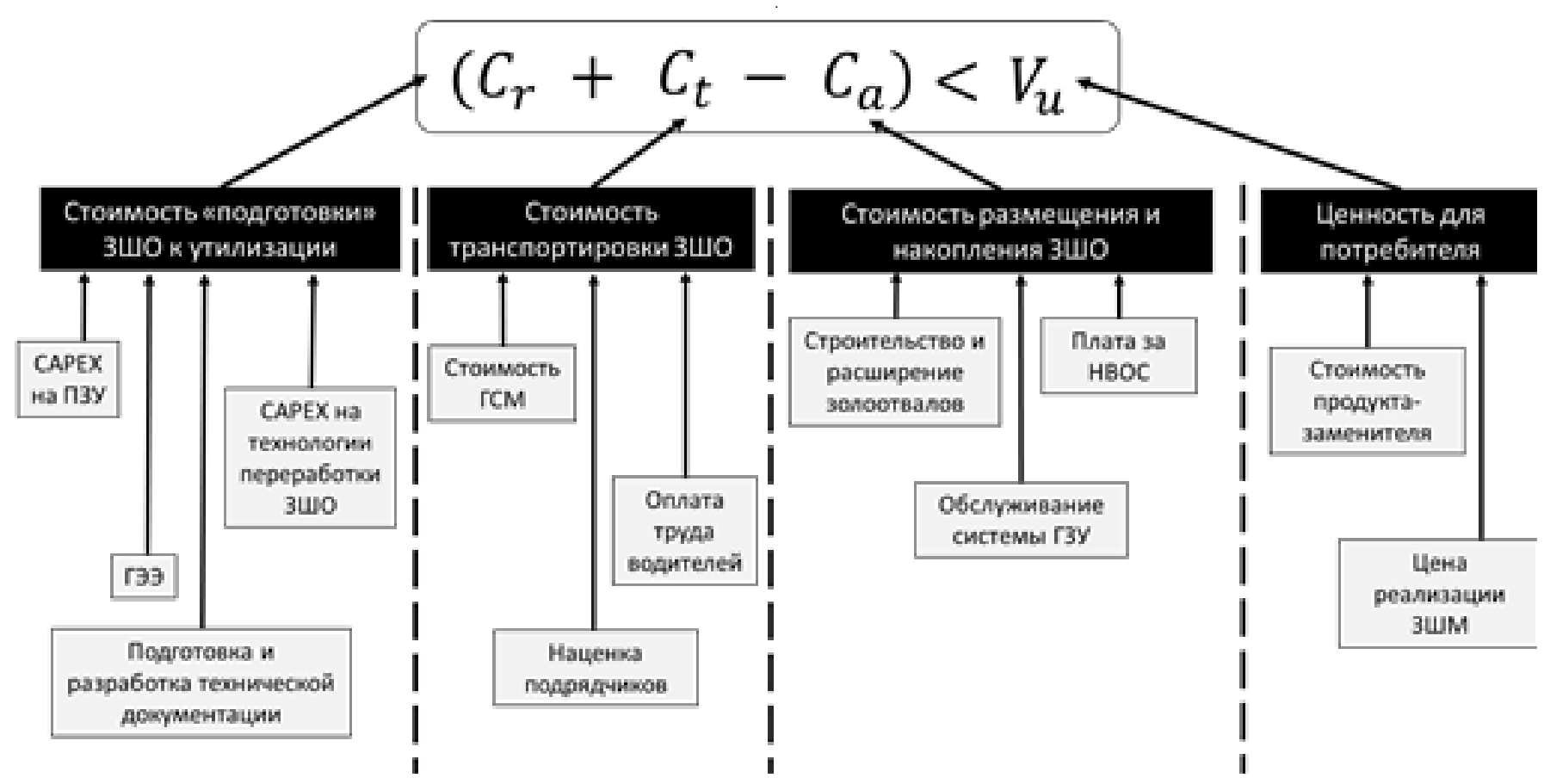

Рис. 2. Описание факторов, определяющих экономическую целесообразность утилизации ПСТТ-ЗшО. Источник: подготовлено автором на основе Ward C., Heidrich C., Yeatman [1]

в России на данном этапе. Тогда как существенные капитальные затраты на переоборудование систем золоудаления, сертификацию продукции и несение транспортных расходов ТЭС при текущей системе регулирования должны компенсировать за счет собственных источников.

Отдельным направлением является стимулирование развития и использования технологий, которые могли бы увеличивать ценность ЗШМ для потребителей. В данном случае можно говорить о необходимости развития высокотехнологичной переработки ПСТТ-ЗШО либо через регуляторные механизмы повышать спрос на продукцию, произведенную с использованием ЗШМ. Нефинансовые стимулирующие инструменты утилизации ПСТТ-ЗШО широко распространены в Индии. Для обеспечения использования золы-уноса в качестве добавки при дорожном строительстве ТЭС берут на себя обязательства по предоставлению строительной организации соответствующих сертификатов на золошлаки. Согласно действующему законодательству, стоимость транспортировки ЗШО в радиусе 100 км полностью покрывается генератором, а в радиусе 300 км делится между генератором и потребителем [10].

\section{Зак^ючение}

Решение задачи повышения объемов утилизации ПСТТ-ЗШО в России потребует комплекса мероприя- тий как по формированию экономических стимулов, так и регуляторных мер и ограничений, направленных на снижение целесообразности размещения ПСТТЗшО на золошлакоотвалах. Тем самым, можно выделить следующие направления изучения данной проблемы:

- снижение стоимости технологий ПЗУ по переработке ПСТТ-ЗШО;

- снижение затрат ТЭС на сертификацию ПСТТ-ЗШО в качестве продукции (ЗШМ);

- совершенствование цепей поставок ЗШМ для потребителей (например, с использованием железнодорожного транспорта);

- снижение целесообразности и возможности размещения ПСТТ-ЗШО на золошлакоотвалах (например, ограничение на ввод новых ОРО);

- стимулирование разработки и внедрения технологий, позволяющих извлекать высокую добавленную стоимость из ЗШМ;

- повышение спроса на ЗШМ и продукцию, произведенную с применением ЗШМ (например, установление требований по использованию продукции, произведенной с использованием техногенных материалов для нужд государственного и муниципального заказа).

Все перечисленные аспекты потребуют детальной проработки в будущих исследованиях с использованием эмпирических данных. 


\section{ЛИТЕРАТУРА}

1. Ward C., Heidrich C., Yeatman 0. Coal combustion products handbook: Second edition //Cooperative Research Centre for Coal in Sustainable Development, Ash Development Association of Australia: Australia. — 2014.

2. Gurba L., Heidrich C., Ward C. Coal combustion products handbook //Cooperative Research Centre for Coal in Sustainable Development, Australian Black Coal Utilisation Research Limited: Australia.— 2014.

3. Лунев А. А. Обоснование расчетных значений механических характеристик золошлаковых смесей для проектирования земляного полотна: дис. канд. тех. наук: 05.23.11. Омск, 2019.

4. Постановление Правительства РФ от 13.09.2016 N913 (ред. от 24.01.2020) «0 ставках платы за негативное воздействие на окружающую среду и дополнительных коэффициентах» // Консультант плюс URL: http://www.consultant.ru/document/cons_doc_LAW_204671/ (дата 0бращения: 25.02.2020).

5. $0 б$ утверждении Правил технической эксплуатации электрических станций и сетей Российской Федерации (с изменениями на 13 февраля 2019 года) // Техэксперт URL: http://docs.cntd.ru/document/901865958 (дата обращения: 20.03.2020).

6. РД 153-34.0-02.108-98 «Рекомендации по борьбе с пылением действующих и отработанных золошлакоотвалов TЭG» // Pocteпло URL: https://www. rosteplo.ru/Npb_files/npb_shablon.php?id=2098 (дата обращения: 20.03.2020).

7. РД 34.02.303-91 0траслевая инструкция по нормированию вредных выбросов в атмосферу для тепловых электростанций и котельных // Будстандарт URL: http://online.budstandart.com/ru/catalog/doc-page?id_doc=59742 (дата обращения: 20.03.2020).

8. Shu-Hua Ma. et al. Challenges and Developments in the Utilization of Fly Ash in China // International Journal of Environmental Science and Development — 2017 — T. 8. — № . 11. — C. 781-785.

9. Gurba L., Heidrich C., Ward C. Coal combustion products handbook //Cooperative Research Centre for Coal in Sustainable Development, Australian Black Coal Utilisation Research Limited: Australia.— 2014.

10. Venktesh Sharma. et al. Trends in Utilization of Coal Fly Ash in India: A Review // Journal of Engineering Design \& Analysis — 2019 — T. 2. — № . 12-16. C. 13-16.



